\title{
MAPEAMENTO DE ERAGROSTIS PLANA NESS (CAPIM-ANNONI) POR MEIO DE IMAGENS ORBITAIS
}

\author{
Nelson Cicconet ${ }^{1}$ \\ Jose Maria Fillippini Alba ${ }^{2}$ \\ Rosangela Lurdes Spironello ${ }^{3}$ \\ Henrique Cunha ${ }^{4}$
}

Resumo: A espécie Eragrostis plana Nees, popularmente conhecido como Capim-annoni, é uma planta originária da África, que foi introduzida no Sul do Brasil, provocando a infestação de boa parte do Pampa Gaúcho, com registros de ocorrência em outros estados brasileiros. Este trabalho objetivou identificar, através de imagens de satélites de alta resolução espacial, com suporte de levantamento no campo, a ocorrência e a intensidade da infestação por capim-annoni em um recorte do município de Santana do Livramento, RS. O capimannoni está presente em aproximadamente 17\% da área, na média das três imagens estudadas. Foram consideradas seis classes de uso da terra, cuja maior variação parece associada ao contraste inverno - verão. O método permitiu visualizar a distribuição do capim-annoni e sua dinâmica, permitindo uma avaliação eficiente da área de estudo que poderá ser estendida para toda a região.

Palavras-Chave: Capim-Annoni; Pastagem; Sensoriamento Remoto; Uso Da Terra.

\section{MAPPING ERAGROSTIS PLANA NESS (GRASS LOVEGRASS) BY MEANS OF ORBITAL IMAGES}

Abstract: Eragrostis plana Nees or, popularly, grass lovegrass, is an African plant introduced in Southern Brazil some years ago which infested a part of the Pampa biome, with occurrences in several Brazilian states. The present work intended the identification of grass lovegrass their occurrence and intensity of the infestation through satellite imagery of high resolution, with support of field survey in a sector of the municipality of Santana do Livramento, Rio Grande do Sul State. The grass lovegrass occurs as a mean value in about $17 \%$ of the area. Six classes of land use were considered, with amplitude related to wintersummer contrast. The method allows an evaluation of grass lovegrass distribution and it's dynamic in the study region with potential for extension for all region.

Key Words: Grass Lovegrass; Land Use; Pasture; Remote Sensing.

1. Geógrafo pela UFPEL, Mestrando em Geografia pela Universidade Federal de Santa Maria (UFSM), (ncicconeto@gmail.com).

2. Dr. em Geociências, Pesquisador: Embrapa Clima Temperado (jose.filippini@embrapa.br).

3. Dra. em Geografia, Docente: Universidade Federal de Pelotas (UFPEL), (spironello@gmail.com).

4. Licenciado em Geografia, Mestrando em sensoriamento remoto pela UFRGS, (henriquecunha@gmail.com). 


\section{INTRODUÇÃO}

A análise espacial através do processamento digital de imagens obtidas por sensoriamento remoto tem se tornado prática de uso comum. Crosta (1993), já comentava que o uso dessas imagens faz parte do cotidiano de várias ciências, destacando ainda a eficiência, confiabilidade e o baixo custo do uso de imagens digitais em monitoramentos ambientais de diversas escalas.

Nos dias atuais, vários autores de ciências ligadas à terra e ao meio ambiente destacam a importância e apontam métodos de utilização de imagens obtidas por sensoriamento remoto. Florenzano (2007), Meneses e Almeida (2012) e Santos (2010), estão entre alguns dos autores que discorrem sobre o assunto e, também, apontam métodos e procedimentos de análise espacial, tendo como base, imagens de satélite ou fotografias aéreas.

Dentro deste contexto, podemos analisar a ocorrência de infestação do Capim-annoni em um recorte espacial específico localizado no município de Santana do Livramento, no Rio Grande do Sul, incluindo o campo eólico de Cerro Chato, inaugurado em maio de 2011 (ZERO HORA, 2012).

Localizado no sudoeste do Rio Grande do Sul, Santana do Livramento, está inserido no Bioma Pampa (IBGE, 2004). Região formada basicamente por campos (BOLDRINI, 2009), sendo que a agropecuária é a atividade mais antiga da região e, talvez, a mais importante. Ainda segundo Boldrini (2009), embora possa parecer o contrário, o Bioma Pampa é muito complexo em se tratando de biodiversidade, cobrindo grandes extensões de relevo suavemente ondulado. Esta cobertura original está, no presente, bastante ameaçada pela substituição das espécies nativas através de praticas agrícolas comerciais (BOLDRINI, 2009). Com isso, pode ocorrer a introdução de espécies exóticas, não nativas do local, podendo causar desequilíbrios a este bioma tão frágil.

Uma destas espécies consideradas invasoras é a espécie Eragrostis plana Nees, mais popularmente conhecido como Capim-annoni. Trata-se de uma planta originária da África, que foi introduzida no Sul do Brasil na década de 1950 (MEDEIROS, et al. 2009), sendo encontrada em boa parte do Pampa Gaúcho em diversos níveis de infestação. Sua ocorrência no DF e nos Estados de SC, SP, MG, MS, MT, TO e PA já é conhecida (REIS, 1993). 
Segundo Medeiros et al., (2009), plantas invasoras como o Capim-annoni, podem trazer sérios danos às atividades econômicas desenvolvidas em sua área de ocorrência. No caso específico do Capim-annoni, a planta não é uma boa forrageira para a alimentação de bovinos e ovinos. É também preterido no pastejo destes animais, o que pode oferecer uma "vantagem" competitiva em relação às outras espécies usadas comercialmente na configuração da pastagem da região. Estes aspectos representam um dano considerável ao ambiente natural do Pampa Gaúcho e também prejuízos socioeconômicos.

Ainda neste sentido, Goulart et al. (2009), discorrem sobre este tema ressaltando os problemas causados pela infestação do Capim-annoni sobre a vegetação campestre do Rio Grande do Sul. Os autores dão também uma ideia da forma de disseminação da referida planta daninha (GOULART et al. 2009). Os autores também afirmam que seu valor nutritivo é baixo, causando desse modo, problemas econômicos ao setor pecuário e também gerando perda de biodiversidade. Os autores destacam que, através de sucessivas aplicações de herbicidas para o controle desta invasora, podem ocorrer perdas de espécies nativas, causando ainda mais desequilíbrios.

Ainda neste contexto, Medeiros e Focht (2007), destacam que as espécies invasoras, entre elas o Capim-annoni, se estabelecem quando há desequilíbrios entre a oferta de recursos para estas espécies. Havendo oferta de recursos em excesso e ocorrendo a introdução, voluntária ou não, de uma espécie exótica, a probabilidade desta causar diversos danos ao meio onde ela foi inserida é grande. Especificamente relacionado ao Capim-annoni, encontra ambiente adequado à sua expansão próximo a estradas, locais com pastejo excessivo, área de descanso de animais e uso intensivo do solo (MEDEIROS; FOCHT, 2007).

Assim sendo, o objetivo central deste trabalho é identificar, através de imagens de satélites de alta resolução espacial, a ocorrência e a intensidade da infestação por Capim-annoni neste referido espaço geográfico no contexto de projeto sobre o assunto em desenvolvimento pela Embrapa junto a diversas entidades do estado (UFRGS, UNIPAMAPA, UFPEL, FEPAGRO, EMATER). Recursos fotográficos no campo foram utilizados para analisar o comportamento dessa forma de pastagem. 


\section{MATERIAIS E MÉTODOS}

Para a elaboração do presente trabalho, utilizou-se um recorte de imagem do satélite IKONOS de 13-09-2011, com resolução espacial de 2,5m e com quatro bandas espectrais: azul (450-520nm); verde (520-600nm); vermelho (630-690nm) e infravermelho próximo (760-900nm). Também outro recorte de imagem do satélite RAPIDEYE, com duas datas diferentes (01-07-2011 e 17-01-2012). As duas imagens do tem resolução espacial de 5m e cinco bandas espectrais: azul (440-510nm); verde (520-590nm); vermelho (630-685nm); borda vermelha (690-730nm) e infravermelho próximo (760-850nm). As imagens orbitais foram adquiridas com recursos públicos em 2012-13 junto à empresa ENGESAT (Curitiba, $P R)$, especificamente para a pesquisa sobre o capim-annoni.

Consideraram-se informações levantadas no campo em 17 de agosto de 2012 e 16 de abril de 2013, incluindo fotos das áreas avaliadas e localização via receptor GPS para validar a referida pesquisa. Para isso se lançou mão de um receptor de GPS Garmin e uma máquina fotográfica Nikon ${ }^{\circledR}$, modelo D40.

Todas as imagens tiveram tratamento, considerando o processamento digital por meio do histograma de cada banda (CROSTA, 1993), utilizando o software SPRING 5.2.3 (SANTOS, 2010). Esse processo é necessário para conseguir uma melhor visualização e destacar a resposta dos pixels de interesse. Testaram-se vários métodos de classificação, sendo esses métodos, aplicados nas três imagens utilizadas no trabalho. Foram aplicados testes de classificação supervisionada e não supervisionada (SANTOS, 2010). A diferenciação do Capim-annoni em relação ao restante da vegetação se mostrou muito difícil de ser observada nos diversos procedimentos ensaiados.

Optou-se por aplicar o método de classificação "crescimento de regiões" que é uma técnica de agrupamento de dados, na qual somente as regiões adjacentes, espacialmente, podem ser agrupadas. Levaram-se em conta dois parâmetros importantes: Similaridade e Área que segundo definição do INPE (2007), disponível na literatura, nos diz que a medida de similaridade está baseada na distancia Euclidiana entre os valores médios dos níveis de cinza de cada região. Assim, duas regiões são consideradas distintas se a distância entre suas médias for superior ao limite de similaridade escolhido. Também, as regiões com área menor que o mínimo escolhido, são absorvidas pelas regiões adjacentes mais similares a 
estas últimas. Este método utiliza, além da informação espectral de cada pixel, a informação espacial que envolve a relação com seus vizinhos. Reconhece áreas homogêneas das imagens, baseando-se nas propriedades espectrais e espaciais das mesmas. A informação de borda é usada para separar as regiões e as propriedades espectrais e espaciais que unem as áreas com a mesma textura ou com textura semelhante (OLIVEIRA, et al., 2003).

Também se fez uma tentativa de classificação supervisionada pixel a pixel também no software Spring (5.2.3). Esta consiste na informação espectral de cada pixel para achar regiões homogêneas. Estes classificadores podem ser separados em métodos estatísticos (probabilidades) e determinísticos (não utilizam probabilidades) (OLIVEIRA, et al., 2003).

Os dois métodos foram aplicados nas três imagens descritas acima. Entretanto, a melhor resposta foi obtida na imagem IKONOS, quando se realizou uma classificação por regiões. Testaram-se várias combinações entre similaridade e área de pixels, considerando os pares de valores de 5 e 10; 10 e 400; 20 e 400; 50 e 100; 5 e 100; 5 e 50; 10 e 100 respectivamente. A relação de similaridade com valor de 5 e número de pixels igual a 10 foi considerada a mais adequada em função da comparação visual do resultado da classificação (polígonos) com a imagem Ikonos de setembro de 2011 e os dados levantados no campo. Para ter uma maior confiabilidade nos resultados, aplicou-se o mesmo método para as três imagens diferentes.

A partir dos polígonos gerados, colheram-se amostras aleatórias dos diversos usos possíveis dentro da área de estudo, de forma visual, procurando definir áreas de uso homogêneo. Definiram-se seis classes de uso, conforme o IBGE (2006), adaptadas para a área de estudo. As classes definidas são: Corpos de água, Capim-annoni, Macega, Pastagens, Solo e Vegetação. Algumas pequenas áreas não foram classificadas.

Quando se aborda a Vegetação, optou-se por reunir toda a composição florestal em uma só classe. Tanto a Vegetação arbórea, quanto a arbustiva não tem muita representatividade na área de estudo e, principalmente, não é o foco deste trabalho. Quanto à classe "Macega", trata-se da espécie Paspalum regnellii Mez (Macega do banhado), encontrada com certa frequência no Pampa Gaucho (MEDEIROS, et al. 2009).

Partindo desse pressuposto, partiu-se para a classificação, onde se usou o classificador "Bhattacharya" com limiar de aceitação de $99 \%$ num teste e com 99,9\% no outro, sendo que 
o utilizado foi o limiar 99\%. Este classificador é um algoritmo que requer a seleção de áreas de treinamento, podendo ser as regiões separadas durante o processo de segmentação ou polígonos das regiões a serem classificadas. Utiliza as amostras de treinamento para calcular a função de densidade de probabilidade das classes apontadas no treinamento. Após isso, analisa, em cada região, a distância de Bhattacharya entre as classes (MOREIRA, 2010).

\section{RESULTADOS E DISCUSSÃO}

Primeiramente optou-se pela apresentação de alguns registros fotográficos em alguns locais estratégicos dentro da área de estudo. Posteriormente serão apresentados os mapas realizados, notando-se que há uma correspondência entre as fotografias apresentadas e os mapas, dando uma maior confiabilidade ao trabalho de mapeamento.

Dentro desta perspectiva, apresenta-se a seguir as figuras de representação, tanto das fotografias, como dos mapas.

A Figura 1 mostra uma área de ocorrência de infestação com o Capim-annoni dentro da área estudada.

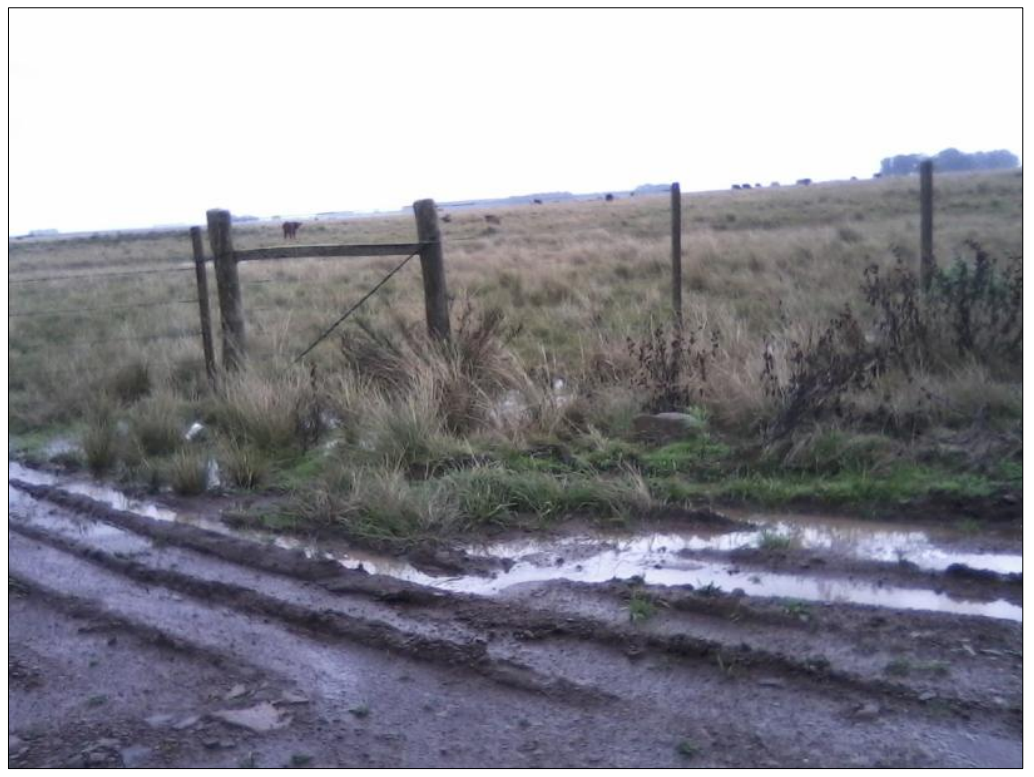

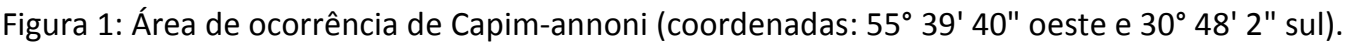
Fonte: Jose Maria Fillipini Alba (2013) Acervo pessoal.

Através desta fotografia, percebe-se que a região apresenta pouca declividade, o que permite uma visualização da infestação do Capim-annoni, num primeiro plano, sendo mesclado com uso do solo por Pastagens. Vale destacar que a localização desta área 
coincide com o mapeamento realizado com as três imagens utilizadas. É uma área a nordeste dos mapas apresentados, onde a ocorrência deste tipo de uso foi verificada através do processamento digital das imagens de satélite. Cabe destacar que é relativamente comum encontrar nessa área de abrangência, a inserção do gado, o qual é criado em sistema extensivo, o que pode 'justificar' a extensa quantidade de área de pastagem e a presença do Capim-annoni.

Outra porção da área de estudo está representada na Figura 2. Nela percebe-se a ocorrência também do Capim-annoni. Percebe-se também que a classe "Pastagens" está um tanto degradada, podendo ser um indício de excesso de lotação animal, contribuindo para a proliferação da espécie invasora pelo pisoteio e também pela maior quantidade de fezes contendo suas sementes (MEDEIROS; FOCHT, 2007).

Ainda com relação a esta fotografia, veem-se ao fundo algumas torres de produção de energia eólica, pois a área de estudo contém um parque eólico chamado Cerro Chato.

Percebe-se também, algumas pequenas porções de Vegetação, fazendo parte da paisagem. Algumas destas porções foram implantadas em áreas aleatórias, de espécies exóticas, para servirem de sombra e abrigo eventual aos animais. Outras porções são nativas do Bioma Pampa, vindo a serem os "Capões de Mato", muito populares dentro da cultura dos trabalhadores do campo desta importante porção do estado do Rio Grande do Sul (SUERTEGARAY; SILVA, 2009).

Nestas fotografias fica evidente a complexidade da área de estudo no que tange ao uso do solo. As diferenças na paisagem são, em alguns casos, muito sutis, dificultando sobremaneira o processamento digital das imagens para posterior mapeamento dos usos do solo. 


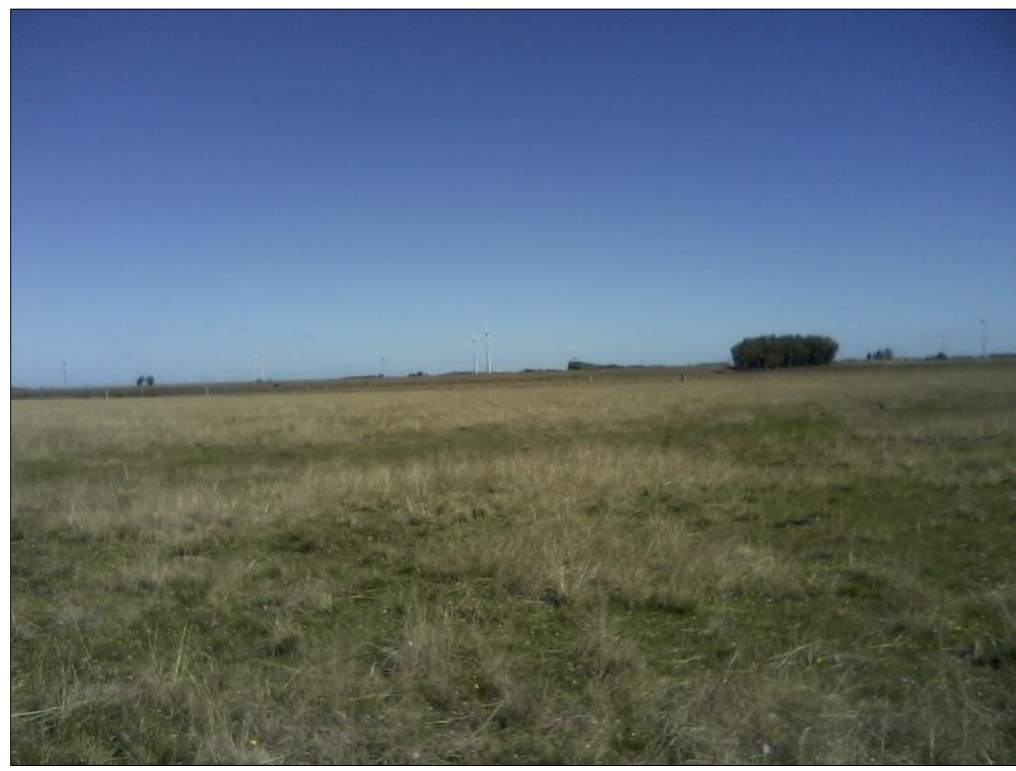

Figura 2. Área com ocorrência alternada de Pastagem e Capim-Annoni dentro da área de estudo (coordenadas: $55^{\circ} 42^{\prime} 26^{\prime \prime}$ oeste e $30^{\circ} 47^{\prime} 48^{\prime \prime}$ sul).

Fonte: Jose Maria Fillipini Alba (2013) Acervo pessoal.

Ainda como resultado deste estudo, foram obtidos três produtos cartográficos, referentes às três imagens usadas como base para esta investigação.

A Figura 3 nos mostra o resultado desta investigação na forma de produto cartográfico. Nela está representado o mapa referente à imagem do satélite Ikonos com data de 13-09-2011. 0 Capim-annoni localiza-se, basicamente, na área a nordeste do mapa, representado pela cor amarela, na legenda do mesmo. Ocorre também em outras partes, principalmente próximo a estradas, caminhos e áreas onde o pastejo possivelmente possa ser mais intenso. Destacase, contudo, que a classe de uso Pastagens, se apresenta de maneira bem expressiva, sempre adjacente às áreas ocupadas por Capim-annoni. As demais classes ocorrem em menor proporção e de forma bem dispersa na área de abrangência desta imagem. 


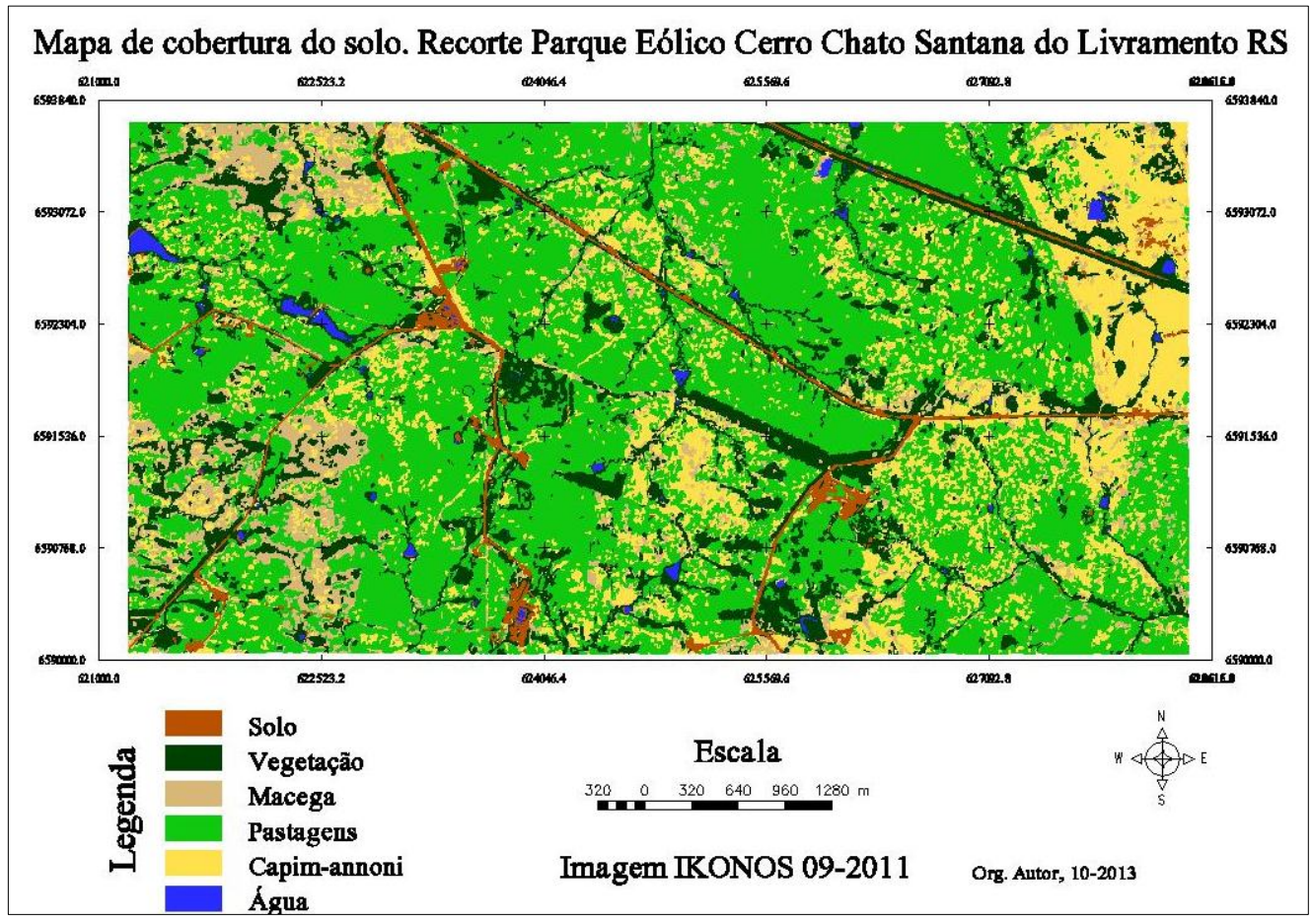

Figura 3. Mapa de usos do solo da área de estudo.

Fonte: Nelson Cicconet (2013).

A Figura 4 representa o mapa de uso do solo na mesma área, para o qual foi usada a imagem do satélite Rapideye, de 01-07-2011.

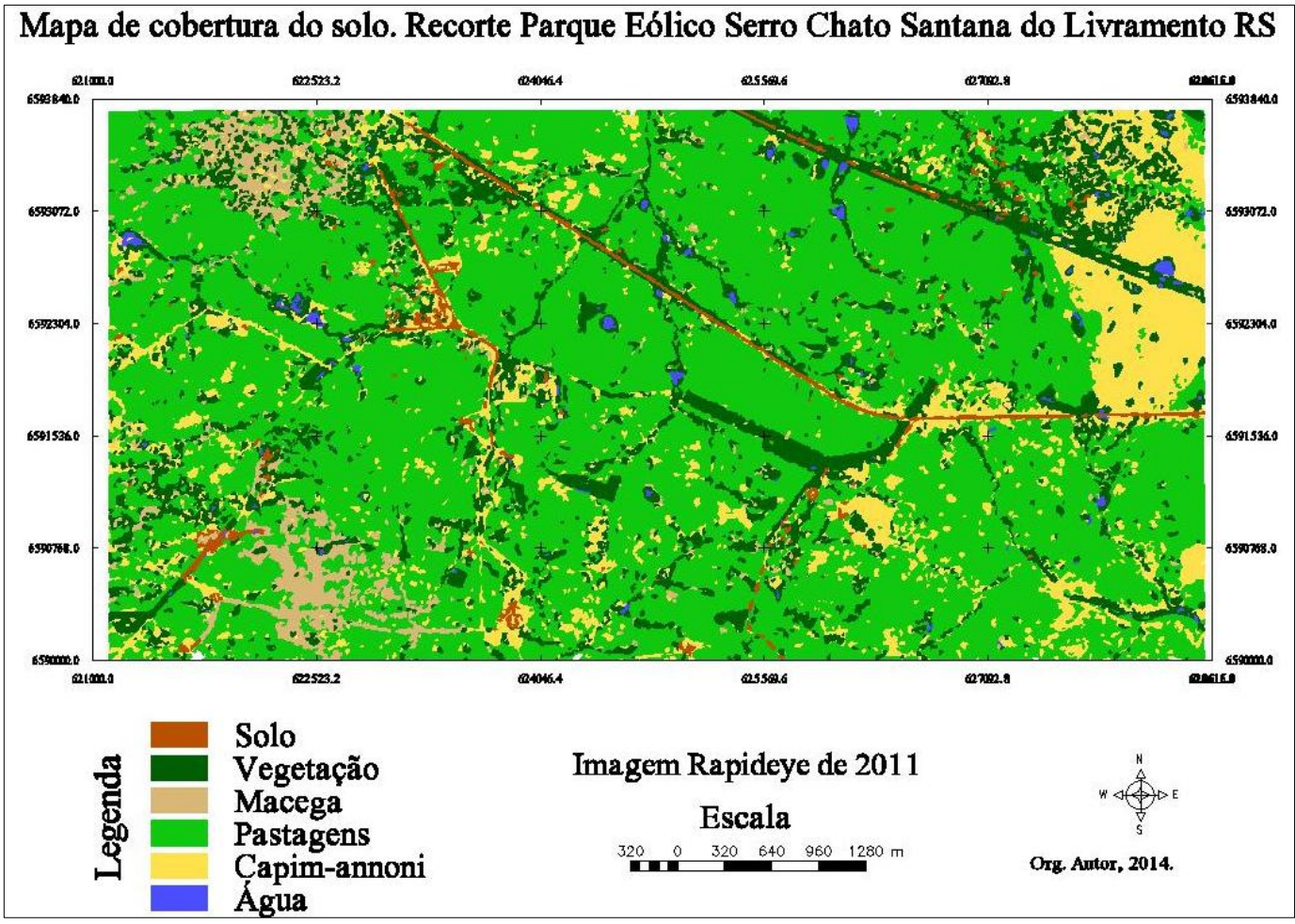

Figura 4. Mapa de usos do solo na área de estudo. Fonte: Nelson Cicconet (2013). 
Neste mapa também procede a percepção de maior ocorrência do Capim-annoni a nordeste da área delimitada. Também há a ocorrência ao longo de estradas e caminhos, representando quase que as mesmas áreas dos dois mapas ocupados com os mesmos usos. Este aspecto é bastante relevante, principalmente levando-se em conta a diferença de resolução das duas imagens estudadas (a imagem Ikonos possui resolução espacial de 2,5m e a Rapideye tem resolução espacial de $5 \mathrm{~m}$ ).

No entanto, deve-se levar em conta a proximidade das datas das duas imagens representando os mapas das figuras 03 e 04. Essas imagens têm pequenas diferenças de datas (a imagem Ikonos é de 13-09-2011 e a do Rapideye é de 01-07-2011), estando as duas dentro da mesma estação do ano. Seguindo este raciocínio, todos os usos representados estariam dentro da mesma faixa de vegetação (BOLDRINI, 2009) e poderia ocorrer certa semelhança entre os dois mapas.

No entanto, esta semelhança não é vista quando os usos são quantificados. Através da Tabela 1, se apresentam esses usos através de valores em hectares e suas respectivas porcentagens. Nesta tabela, verifica-se que os usos coincidem quando se analisa as imagens com resolução igual (a resolução espacial do Rapideye é de $5 \mathrm{~m}$ ) e difere relativamente em relação à imagem Ikonos que possui resolução espacial de $2,5 \mathrm{~m}$.

Na Figura 5 é apresentado o mapa de usos da área delimitada para o estudo através do processamento da imagem Rapideye de 17-01-2012. 


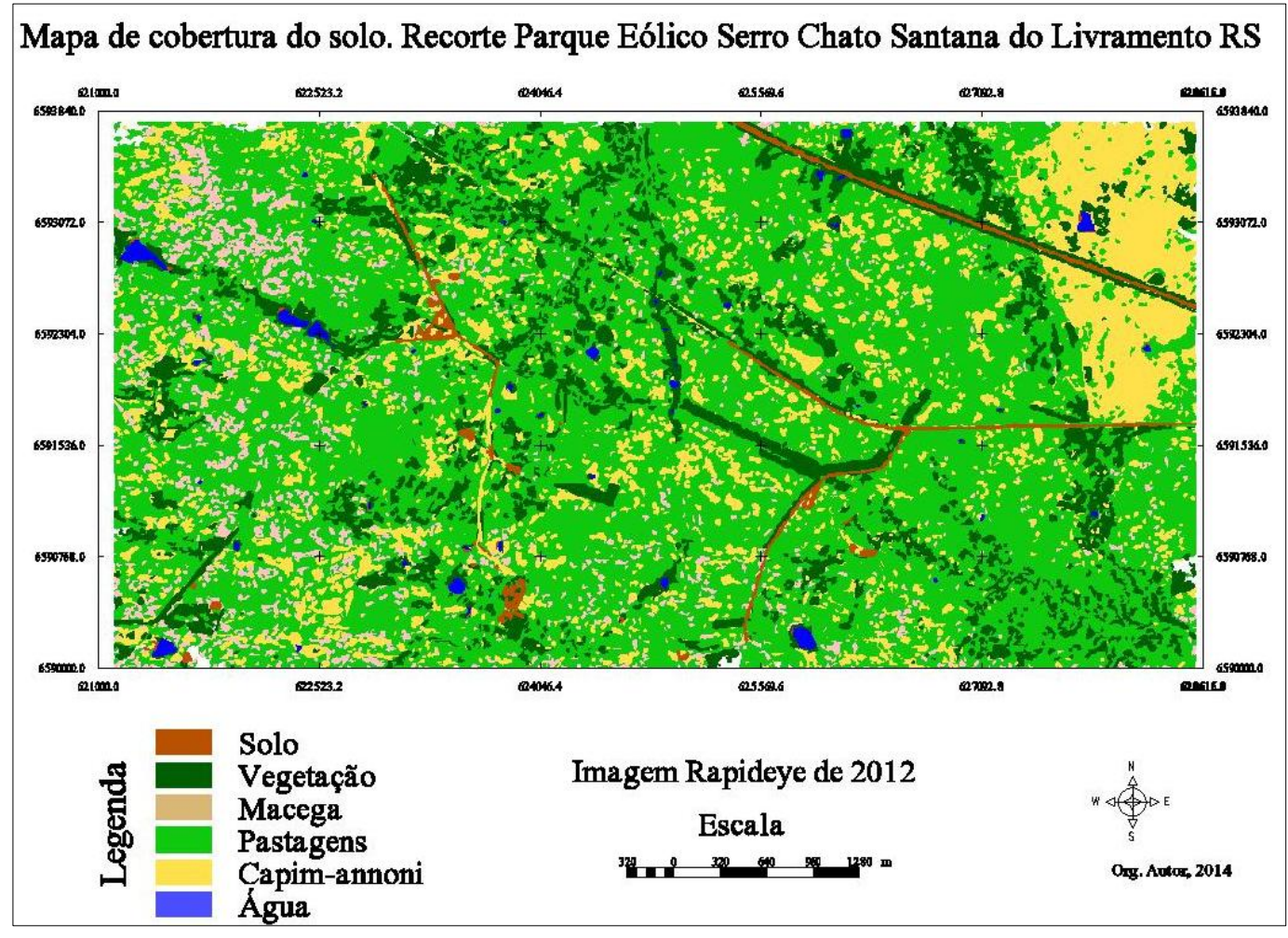

Figura 5. Mapa de usos na área de estudo.

Fonte: Nelson Cicconet (2013).

Neste mapa também o Capim-annoni tem sua maior ocorrência na mesma área dos outros dois mapas (figuras 03 e 04), ou seja, a nordeste dos três produtos cartográficos. Mas neste último (Figura 5), sua ocorrência não é percebida ao longo das estradas e caminhos dentro da área de estudo. Está, ao contrário, disposto por toda a extensão do mapa em pequenas porções pouco conectadas umas com as outras, normalmente circundado pelo uso do solo com Pastagens.

Em termos de quantificação dos usos, pode se notar que há certa homogeneidade entre os três produtos cartográficos expostos acima. Grande parte da área de estudo tem como cobertura, o uso do solo Pastagens com 63\% de área ocupada, na média, das três imagens. 0 Capim-annoni está presente em aproximadamente $17 \%$ da área, na média das três imagens estudadas. É representado em 14,72\% e 15,84\% da área de estudo, analisada através da imagem do Rapideye de duas datas diferentes. Os outros usos também apresentaram relativa uniformidade de ocorrência nas três imagens estudadas. Destaca-se que para fins de análise, para a presente pesquisa, o foco concentra-se na classe de uso do solo "Capimannoni" para as três imagens trabalhadas, sendo os demais usos analisados de forma superficial, entretanto, não os excluindo da análise na sua totalidade. 
Outro fator a ser considerado é o fato das imagens serem de estações diferentes do ano. Duas são da temporada de inverno (13-09-2011 e 01-07-2011) e uma do verão. No entanto, não foi encontrado na literatura consultada, ou não há estudos conclusivos que possam afirmar diferenças de resposta espectral do mesmo alvo (Capim-annoni) para distintas estações do ano.

Há a hipótese de que esta diferente resposta espectral possa ocorrer, mas somente poderá ser efetuada a comprovação através de estudos futuros. Por hora, fica-se no campo da hipótese.

A proposta da presente pesquisa, a partir das imagens selecionadas e utilizadas para o mapeamento, aponta sobre alguns aspectos principais, os quais podem ser verificados, considerando que: onde houve a ocorrência de Capim-annoni, o mesmo se mostrou nas três imagens estudadas. Esse fato se repetiu em praticamente todos os seis usos possíveis dentro da mesma área e nas três imagens descritas anteriormente. Estes dados foram dispostos na Tabela 1 para melhor compreensão.

Nesta tabela veem-se os usos do solo quantificados em cada uma das três imagens processadas digitalmente.

\begin{tabular}{|l|c|c|c|c|c|c|}
\hline \multicolumn{1}{|c|}{ IMAGENS } & \multicolumn{2}{c|}{ IKONOS 2011 } & \multicolumn{2}{c|}{ RAPIDEYE 2011 } & \multicolumn{2}{c|}{ RAPIDEYE 2012 } \\
\hline TIPOS DE USO & Hectare & $\mathbf{\%}$ & Hectare & $\mathbf{\%}$ & Hectare & $\%$ \\
\hline Água & 20,36 & 0,77 & 20,23 & 0,72 & 18,17 & 0,65 \\
\hline Capim-annoni & 583,25 & 22,05 & 413,23 & 14,72 & 444,44 & 15,84 \\
\hline Pastagens & 1484,17 & 56,10 & 1882,81 & 67,07 & 1888,67 & 67,30 \\
\hline Macega & 198,11 & 7,49 & 106,29 & 3,79 & 98,16 & 3,49 \\
\hline Vegetação & 307,44 & 11,62 & 351,39 & 12,52 & 315,20 & 11,23 \\
\hline Solo & 52,19 & 1,97 & 32,55 & 1,16 & 27,11 & 0,97 \\
\hline N/classificado & --- & --- & --- & --- & 14,81 & 0,53 \\
\hline Total & 2645,53 & 100 & 2806,52 & 100 & 2806,52 & 100 \\
\hline
\end{tabular}

Tabela 1: Uso e ocupação do solo quantificados nas três imagens estudadas. Fonte: Nelson Cicconet (2013).

\section{CONSIDERAÇÕES FINAIS}

Como a área de estudo apresenta certa homogeneidade com relação aos usos do solo houve certa dificuldade em realizar um mapeamento condizente à realidade.

Os resultados apresentados atenderam aos objetivos propostos deste trabalho. Através das figuras apresentadas, tanto os mapas quanto as fotografias, percebeu-se que o objeto de 
estudo é uma área com relativa homogeneidade dificultando um pouco o trabalho de processamento digital das imagens de satélite.

Os resultados apresentados, no entanto, mostraram-se bastante semelhantes entre uma e outra imagem de satélite. As três imagens apresentaram resultados muito parecidos e através da visita ao campo, pode-se validar os resultados obtidos através do processamento digital e posterior mapeamento da área de estudo.

Neste contexto, pode-se dizer também, que a imagem que mostrou melhores resultados no decorrer do processo realizado foi a imagem do satélite Ikonos. Tendo a mesma uma resolução espacial de 2,5m, pode-se supor que a mesma mostrou os alvos de maneira mais nítida, realçando a diferença entre o Capim-annoni do restante dos alvos.

Mas as outras duas imagens estudadas também mostraram resultados satisfatórios, como mostraram os mapeamentos realizados. Tendo elas a resolução espacial de $5 \mathrm{~m}$, os alvos não tiveram a mesma nitidez da primeira imagem.

Dentro deste contexto, percebe-se a importância das visitas ao campo para validar o trabalho executado em laboratório. Aqui há um complemento do trabalho do laboratório, executando o processamento digital e validando o mesmo através de fotografias em pontos estratégicos dentro da área de estudo.

A partir da coleta de pontos de controle no campo, foi possível avaliar amostras colhidas em campo com as obtidas através dos três mapeamentos obtidos pelos procedimentos descritos neste trabalho.

Assim sendo, entra-se no campo geográfico para a análise e discussão dos resultados obtidos em laboratório, através do mapeamento, com analise do local na área de estudo.

\section{BIBLIOGRAFIA}

BOLDRINI, I.I. A flora dos campos do Rio Grande do Sul. In: CAMPOS SULINOS conservação e uso sustentável da biodiversidade. Valério De Patta Pillar (et al.). Editores. - Brasília: MMA, 2009.

CRÓSTA, A.P. Processamento digital de imagens de sensoriamento remoto. Campinas: Universidade Estadual de Campinas, 1993. $170 \mathrm{p}$.

FLORENZANO, T.G. Iniciação em sensoriamento remoto. São Paulo: Oficina de Textos, 2007.

FOCHT, T. ECOLOGIA E DINÂMICA DO CAPIM-ANNONI-2 (Eragrostis plana Ness), Uma invasora dos campos sulinos: prevenção da sua expansão. Tese de Doutoramento. Universidade Federal do Rio 
Grande Do Sul; Instituto de Biociências; Programa de Pos-Graduação em Ecologia. Porto Alegre, 2008.

GOULART, I.C.G.R; MEROTO JUNIOR, A; PEREZ, N.B; KALSING, A. Controle de Capim-Annoni-2 (Eragrostis plana) com herbicidas pré-emergentes em associação com diferentes métodos de manejo do campo nativo. Planta Daninha, Viçosa-MG, v. 27, № 1, p. 181-190, 2009.

IBGE 2004. Mapa da vegetação do Brasil e Mapa de Biomas de Brasil. IBGE. http://www.ibge.gov.br.

IBGE 2006: Instituto Brasileiro de Geografia e Estatística. Manual Técnico de Uso da Terra. 2ª Edição. 2006.

MEDEIROS, R.B. de; FOCHT, T. Invasão, prevenção, controle e utilização do capim-annoni-2 (Eragrostis plana Nees) no Rio Grande do Sul, Brasil. Pesq. Agrop. Gaúcha, Porto Alegre, v.13, №1, p. 105-114, 2007.

MEDEIROS, R.B. de; SAIBRO, J.C. de; FOCHT, T. Invasão de capim-annoni (Eragrostis plana Nees) no bioma Pampa do Rio Grande do Sul. In: CAMPOS SULINOS conservação e uso sustentável da biodiversidade. Valério De Patta Pillar (et al.). Editores. - Brasília: MMA, 2009.

MENESES, P.R; ALMEIDA, T. de. Org. Introdução ao processamento de imagens de sensoriamento remoto. UNB, Brasília, 2012.

MOREIRA, M. A; Fundamentos do Sensoriamento Remoto e Metodologias de Aplicação 4ํ Ed. São Paulo SP. Oficina de Textos, 2010.

OLIVEIRA, J. C. de; LUIZ, A. J. B; FORMAGGIO, A. R; EPIPHANIO, J. C. N. Avaliação e comparação quantitativa de segmentações por meio do índice IAVAS. XI SBSR, Belo Horizonte, Brasil. 05 a 10 de Abril de 2003, INPE, p $2111-2117$.

REIS, J. C. L. Capim annoni-2: Origem, Morfologia, Características, Disseminação. In: Reunião regional de avaliação de pesquisa com annoni2, 1991, Bagé. Anais. Bagé: EMBRAPACPPSUL, 1993. p. 5-23. EMBRAPA-CPPSUL. Documentos, 7.

SANTOS, A. R. dos; PELUZIO, T. M. de Oliveira; SAITO, N. S. SPRING 5.1.2 PASSO A PASSO. Aplicações Práticas. - Alegre, ES: CAUFES, 2010.

SUERTEGARAY, D. M. A; SILVA, L. A. P. da. Tche Pampa: histórias da natureza gaúcha. In: CAMPOS SULINOS conservação e uso sustentável da biodiversidade. Valério De Patta Pillar. (et al.). Editores. Brasilia: MMA, 2009.

ZERO HORA. Disponível em: http://zerohora.clicrbs.com.br/rs/economia/noticia/2012/06/parqueeolico-do-cerro-chato-e-inaugurado-oficialmente-em-santana-do-livramento-792942.html. Acesso em: 07-08-2013 às 15:00 h.

\begin{tabular}{|r|r|}
\hline Artigo submetido em & $22 / 05 / 2014$ \\
\hline Artigo aceito em & $21 / 01 / 2015$ \\
\hline
\end{tabular}

